\title{
Vascular Variations Associated with Intracranial Aneurysms
}

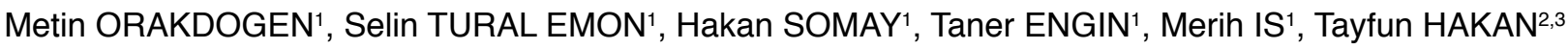 \\ ${ }^{1}$ Haydarpasa Numune Teaching and Research Hospital, Neurosurgery Clinic, Istanbul, Turkey \\ ${ }^{2}$ Kolan International Hospital, Neurosurgery Clinic, Istanbul, Turkey \\ ${ }^{3}$ Okan University, Vocational School of Health Services, Istanbul, Turkey
}

Parts of this study were presented in abstract/oral presentation form at the $29^{\text {th }}$ Annual Scientific Congress of Turkish Neurosurgical Society, Antalya, Turkey, April, 17-21, 2015.

\section{ABSTRACT}

AIM: To investigate the vascular variations in patients with intracranial aneurysm in circle of Willis.

MATERIAL and METHODS: We used the data on 128 consecutive intracranial aneurysm cases. Cerebral angiography images were analyzed retrospectively. Arteries were grouped as anterior cerebral arterial system (ACS), posterior cerebral arterial system (PCS) and middle cerebral arterial system (MCS) for grouping vascular variations. Lateralization, being single/multiple, gender; and also any connection with accompanying aneurysms' number, localization, dimension, whether bleeding/incidental aneurysm has been inspected.

RESULTS: Variations were demonstrated in $57.8 \%$ of the cases. The most common variation was A1 variation (34.4\%). The rate of variations was $36.7 \%, 24.2 \%$ and $10.2 \%$ respectively in ACS, PCS and MCS. MCS variations were significantly higher in males. Anterior communicating artery (ACoA) aneurysm observance rates were significantly higher and posterior communicating artery $(\mathrm{PCoA})$ aneurysm and middle cerebral artery (MCA) aneurysm observance rates were significantly lower when compared to 'no ACS variation detected' cases. In 'PCS variation detected' cases, PCoA aneurysm observance rates and coexistence of multiple variations were significantly higher.

CONCLUSION: The rate of vascular variations in patients with aneurysms was $57.8 \%$. Arterial hypoplasia and aplasia were the most common variations. ACS was the most common region that variations were located in; they were mostly detected on the right side. Coexistence of ACoA aneurysm was higher than PCoA and MCA aneurysms. In the PCS variations group, PCoA aneurysms were the most common aneurysms that accompanying the variation and multiple variations were more common than in the other two groups. The variations in MCS were most common in males.

KEYWORDS: Aplasia, Cerebral aneurysm, Vascular variation, Circle of Willis, Hypoplasia, Microsurgical anatomy

\section{INTRODUCTION}

$\mathrm{T}$ The carotid and vertebrobasilar systems are connected to each other by a polygonal anastomosis channel system that is called 'circulus arteriosus' at the base of the brain. Although Thomas Willis made the first attempt to attribute a function to this anatomy that he described in 1664; his description of the brain became accepted as definitive, appearing in the Bibliotheca Anatomica of 1774-1777 for the first time as the famous 'circle of Willis' in the eighteenth century (25).

Classically, a symmetrical and complete Willis pattern accounts for only $30-50 \%$ of individuals in the population $(1,8,10,27)$. The arteries constituting it may show different variations depending on their hypoplasia, aplasia and fenestration, duplication, trifurcation. These variations may play a considerable role in the development of an aneurysm, 
arteriovenous malformation or cerebrovascular occlusive disease by changing the blood-flow pattern and increasing hemodynamic stress $(3,4,7,12,13,15,23,26,29)$. There are some reports that have investigated the relationship between variations and aneurysm localization in cadaveric $(12,20,28)$ and clinical studies $(14,18,22,31)$.

The aim of this study was to reveal the normal pattern and variation rates in a series of patients operated for intracranial aneurysms and show these variations' gender, localization, lateralization, multiplicity features besides their relationship with aneurysms in several locations, whether bleeding or incidentally diagnosed.

\section{MATERIAL and METHODS}

The study was carried out in a total of 128 consecutive aneurysm cases operated at Haydarpaşa Numune Teaching and Research Hospital between the years 2008 and 2014. Cerebral digital subtraction angiography (DSA) images of each patient and the detailed reports written by neuroradiologists were analyzed retrospectively by two neurosurgeons who practiced neurovascular surgery.

Associated vascular variations of the anterior cerebral, posterior cerebral and middle cerebral arterial system were grouped and studied morphologically:

1) Anterior cerebral artery (ACA) and its branches were assumed as the anterior cerebral arterial system (ACS)

2) Vertebral artery and its branches were assumed as the posterior cerebral arterial system (PCS)

3) Middle cerebral artery (MCA) and its branches were assumed as the middle cerebral arterial system (MCS).

Vascular variations such as hypoplasia, aplasia (absence), duplication, fenestration, trifurcation were noted and lateralization, single or multiple, gender associations and number of aneurysms, localization, diameter, incidental or bleeding aneurysm coexistence with these vascular variations were searched for.

A variation of the circle of Willis was regarded as congenital abnormalities $(5,22)$. Arteries with external diameter less than $1 \mathrm{~mm}$ and communicating arteries smaller than $0.5 \mathrm{~mm}$ were accepted as "hypoplastic" and the absence of the artery as "aplastic" $(1,6,20,28)$. The posterior cerebral artery (PCA) segment of Willis polygon was defined as "fetal type" and "adult type" according to its size.

When visualized $\mathrm{P} 1$ on DSA had smaller size than ipsilateral posterior communicating artery (PCoA) or totally absent, it was accepted as fetal-type origin of PCA; and a P1 segment had the same size as or larger size than PCoA was defined as adult type origin of PCA (15).

\section{Statistical Analyses}

The Number Cruncher Statistical System (NCSS) 2007 \& Power Analysis and Sample Size (PASS) 2008 Statistical Software (Utah, USA) programs have been used for statistical analysis. The Mann-Whitney $U$ test was used for descriptive statistical methods (Mean, Standard Deviation, Median, Frequency, Rate, Minimum, Maximum) and in comparing quantitative data that did not show a normal range/distribution. The Pearson Chi-Square test, Fisher's Exact test and Yates Continuity Correction test (Yates corrected Chi-Square) were used for comparing qualitative data. Significance at a level of $p<0.01$ and $p<0.05$ was obtained.

\section{RESULTS}

The study was carried out on a total of 128 consecutive patients with intracranial aneurysms. The numbers of incidental and bleeding cases were $17.2 \%(n=22)$ and $82.8 \%$ $(n=106)$, respectively. The patients included $55(43 \%)$ men and $73(57 \%)$ women who ranged in age from 16 to 81 years (mean $=52.35 \pm 12.38$ years). Among all cases, 95 (74.2\%) had single aneurysm and 33 (25.8\%) had multiple aneurysms.

Vascular variations were demonstrated in $57.8 \%(n=74)$ of the cases. Variations were single in $40.6 \%(n=52)$ of the cases. There were 2 variations in 18 cases and 3 variations in 4 cases.

\section{Gender}

The differences between variation observance rates $(p=0.426$; $p>0.05)$ and variation number rates $(p=0.083 ; p>0.05)$ by gender were not statistically significant. However, MCS variation observance rates were significantly higher in males than females $(p=0.031 ; p<0.05)$ (Table I).

\section{ACS Variations}

ACS variation was the most frequent occurrence for $36.7 \%$ $(n=47)$ of the cases. The most common variation was A1 variation with $44(34.4 \%)$ cases: 33 had hypoplasia and 11 aplasia. Others were anterior communicating artery (ACoA) fenestration, bilateral pericallosal hypoplasia, and left callosomarginal aplasia. Thirty-one of these cases had single and 16 had multiple variations. The variations were right-sided in $30(68.2 \%)$ cases and left-sided in 14 (31.8\%) (Figure 1AD).

Right-side ACS variations were twice as frequent as those on the left side; $62.8 \%$ of A1 hypoplasia-aplasia variations were on the right side and $31.8 \%$ were on the left side. A1 variations were hypoplasia in 33 cases and aplasia in 11 cases.

The ACS variation rate and ACoA aneurysm coexistence were significantly higher $(p=0.001 ; p<0.01)$ (Table II). Apart from 5 internal carotid artery (ICA) bifurcation aneurysms, there were an additional 6 ICA aneurysms. Three of them were ophthalmic aneurysms, 1 was a superior hypophyseal aneurysm, 1 was a paraclinoid aneurysm and 1 was an ICA wall aneurysm. In these cases, the variation rates were significantly lower $(p=0.005 ; p<0.01)$.

\section{PCS Variations}

PCS variation was observed in 31 (24.2\%) cases with 14 single and 17 multiple variations. P1 hypoplasia/aplasia was the most common variation with $28(21.9 \%)$ cases. In this group, 2 hypoplasia and 1 aplasia were detected in vertebral arteries. The variations were right-sided in 12 (38.7\%) cases, left-sided 
Table I: Variation Rates according to Gender

\begin{tabular}{|c|c|c|c|c|}
\hline & & \multicolumn{2}{|c|}{ Gender } & \multirow{3}{*}{$\mathbf{p}$} \\
\hline & & Male & Female & \\
\hline & & n (\%) & n (\%) & \\
\hline \multirow{2}{*}{ Variation } & No & $21(38.2)$ & $33(45.2)$ & \multirow{2}{*}{${ }^{\mathrm{a}} 0.426$} \\
\hline & Yes & $34(61.8)$ & $40(54.8)$ & \\
\hline \multirow{2}{*}{$\begin{array}{l}\text { Number of variation } \\
(n=74)\end{array}$} & Single variation & $20(58.8)$ & 32 (80.0) & \multirow{2}{*}{ b0.083 } \\
\hline & Multiple variation & $14(41.2)$ & $8(20.0)$ & \\
\hline \multirow{2}{*}{ ACS variation } & No & $13(38.2)$ & $15(37.5)$ & \multirow{2}{*}{ b1.000 } \\
\hline & Yes & $21(61.8)$ & $25(62.5)$ & \\
\hline \multirow{2}{*}{ PCS variation } & No & $21(61.8)$ & $22(55.0)$ & \multirow{2}{*}{ ' 0.725} \\
\hline & Yes & $13(38.2)$ & $18(45.0)$ & \\
\hline \multirow{2}{*}{ MCS variation } & No & $24(70.6)$ & 37 (92.5) & \multirow{2}{*}{ b0.031* } \\
\hline & Yes & $10(29.4)$ & $3(7.5)$ & \\
\hline
\end{tabular}

aPearson chi square test, ${ }^{b}$ Yates Continuity Correction, ${ }^{*} p<0.05$.

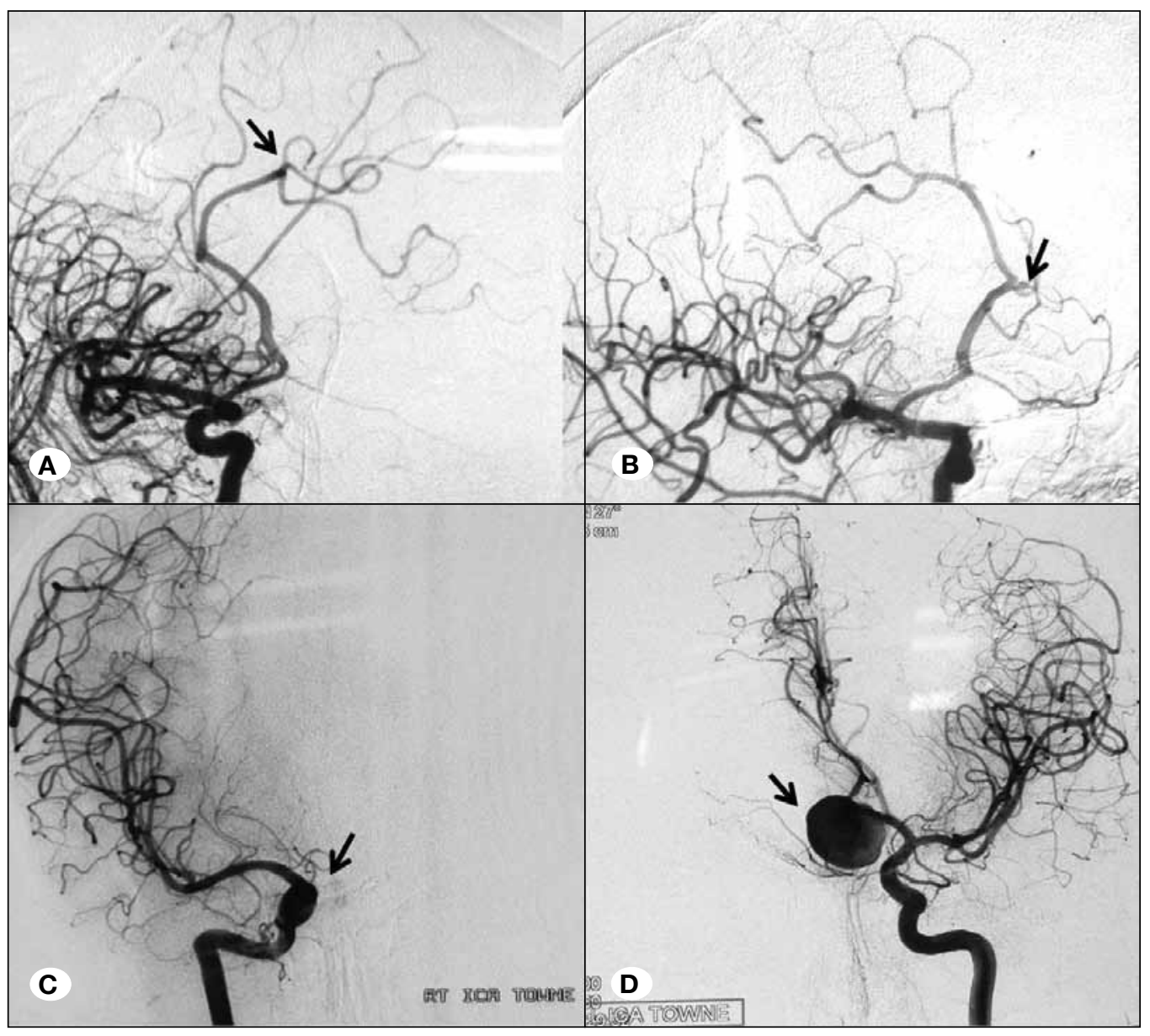

Figure 1: DSA examination showing examples of ACS variations. A) Pericallosal hypoplasia. B) Distal anterior cerebral artery (DACA) aneurysm in the DSA examination of the same patient. C) Right A1 aplasia. D) ACoA aneurysm that fills from left carotid system. 
Table II: Aneurysm Rates according to ACS Variation Presence

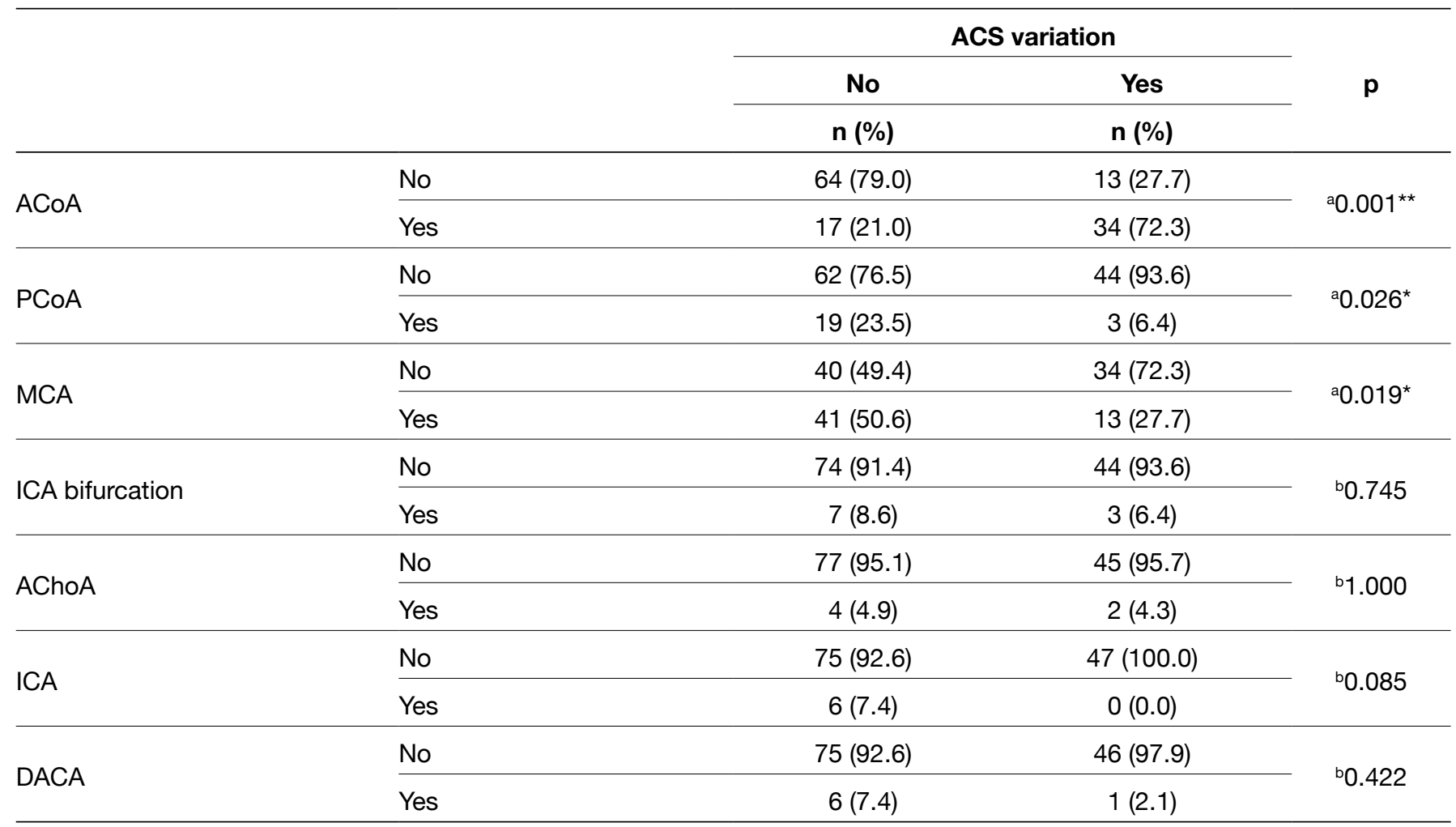

aYates Continuity Correction, ${ }^{b}$ Fisher's Exact Test, ${ }^{*} p<0.05,{ }^{* *} p<0.01$.

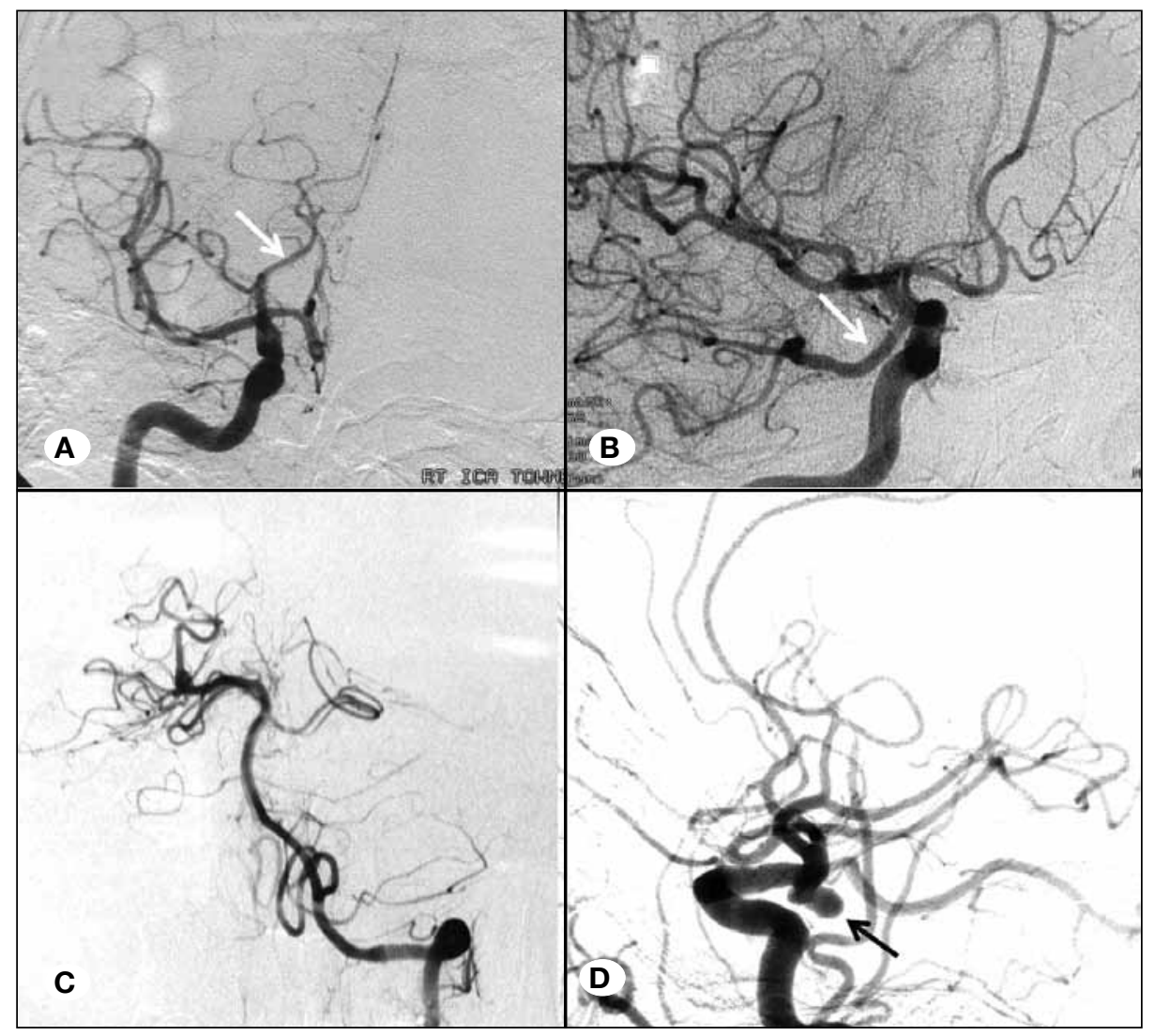

Figure 2: DSA examination showing examples of PCS variations. A) Fetal circulation in AP projection (white arrow). B) Fetal circulation in lateral projection (white arrow). C) AP projections showing P1 aplasia. D) Accompanying PCoA aneurysm in the same patient. 
in $13(42 \%)$ cases and bilateral in $6(19.3 \%)$ cases (Figure 2AD). PCS variation rate and PCoA aneurysm coexistence were significantly higher $(p=0,023 ; p<0.05)$ (Table III).

\section{MCS Variations}

MCS variations were seen in $13(10.2 \%)$ cases; 8 were single and 5 were multiple. One-sided or bilateral MCA trifurcation was the most common variation with $9(7 \%)$ cases. Others were MCA trifurcation and early bifurcation, early bifurcation, MCA duplication, and M2 superior trunk hypoplasia. The variations were right-sided in $4(30.8 \%)$ cases, left-sided in 7 $(53.8 \%)$ cases and bilateral in $2(15.4 \%)$ cases (Figures 3A,B; $4 A, B)$

Table III: Aneurysm Rates according to PCS Variation Presence

\begin{tabular}{|c|c|c|c|c|}
\hline & & \multicolumn{2}{|c|}{ PCS variation } & \multirow{3}{*}{$\mathbf{p}$} \\
\hline & & No & Yes & \\
\hline & & n (\%) & n (\%) & \\
\hline \multirow{2}{*}{$\mathrm{ACoA}$} & No & 60 (61.9) & $17(54.8)$ & \multirow{2}{*}{${ }^{\mathrm{a}} 0.628$} \\
\hline & Yes & $37(38.1)$ & $14(45.2)$ & \\
\hline \multirow{2}{*}{ PCoA } & No & $85(87.6)$ & $21(67.7)$ & \multirow{2}{*}{${ }^{\mathrm{a}} 0.023^{\star}$} \\
\hline & Yes & $12(12.4)$ & $10(32.3)$ & \\
\hline \multirow{2}{*}{ MCA } & No & $53(54.6)$ & $21(67.7)$ & \multirow{2}{*}{ a 0.281} \\
\hline & Yes & $44(45.4)$ & $10(32.3)$ & \\
\hline \multirow{2}{*}{ ICA bifurcation } & No & $89(91.8)$ & $29(93.5)$ & \multirow{2}{*}{ b1.000 } \\
\hline & Yes & 8 (8.2) & $2(6.5)$ & \\
\hline \multirow{2}{*}{ AChoA } & No & 93 (95.9) & 29 (93.5) & \multirow{2}{*}{${ }^{\mathrm{b}} 0.632$} \\
\hline & Yes & $4(4.1)$ & $2(6.5)$ & \\
\hline \multirow{2}{*}{ ICA } & No & $91(93.8)$ & 31 100.0) & \multirow{2}{*}{${ }^{\mathrm{b}} 0.335$} \\
\hline & Yes & $6(6.2)$ & $0(0.0)$ & \\
\hline \multirow{2}{*}{ DACA } & No & $90(92.8)$ & $31(100.0)$ & \multirow{2}{*}{ bo.194 } \\
\hline & Yes & $7(7.2)$ & $0(0.0)$ & \\
\hline
\end{tabular}

aYates Continuity Correction, ${ }^{b}$ Fisher's Exact Test, " $p<0,05$.

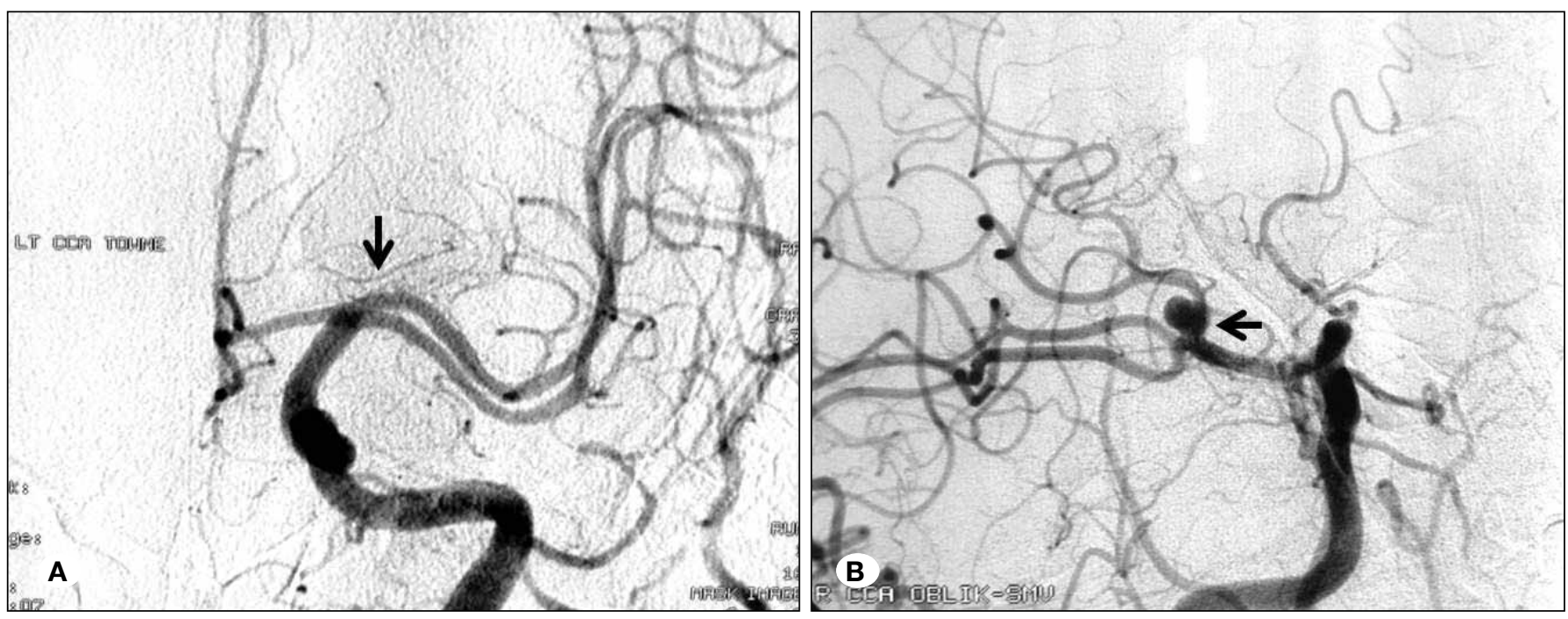

Figure 3: DSA examination showing examples of MCS variations. A) M1 duplication (black arrow). B) MCA aneurysm (black arrow) with trifurcation (right). 
Table IV: Aneurysm Rates according to MCS Variation Presence

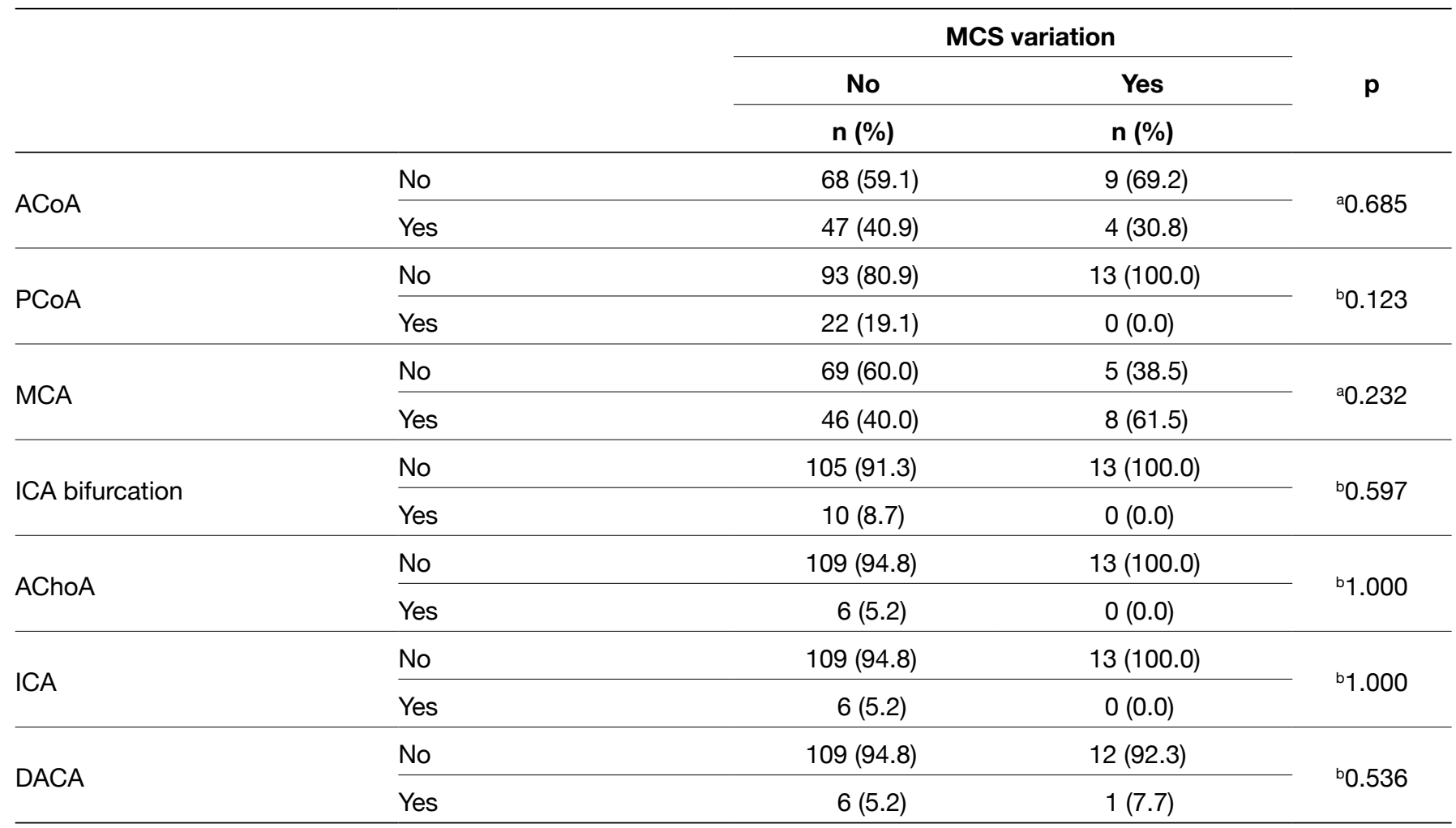

aYates Continuity Correction, 'bisher's Exact Test.

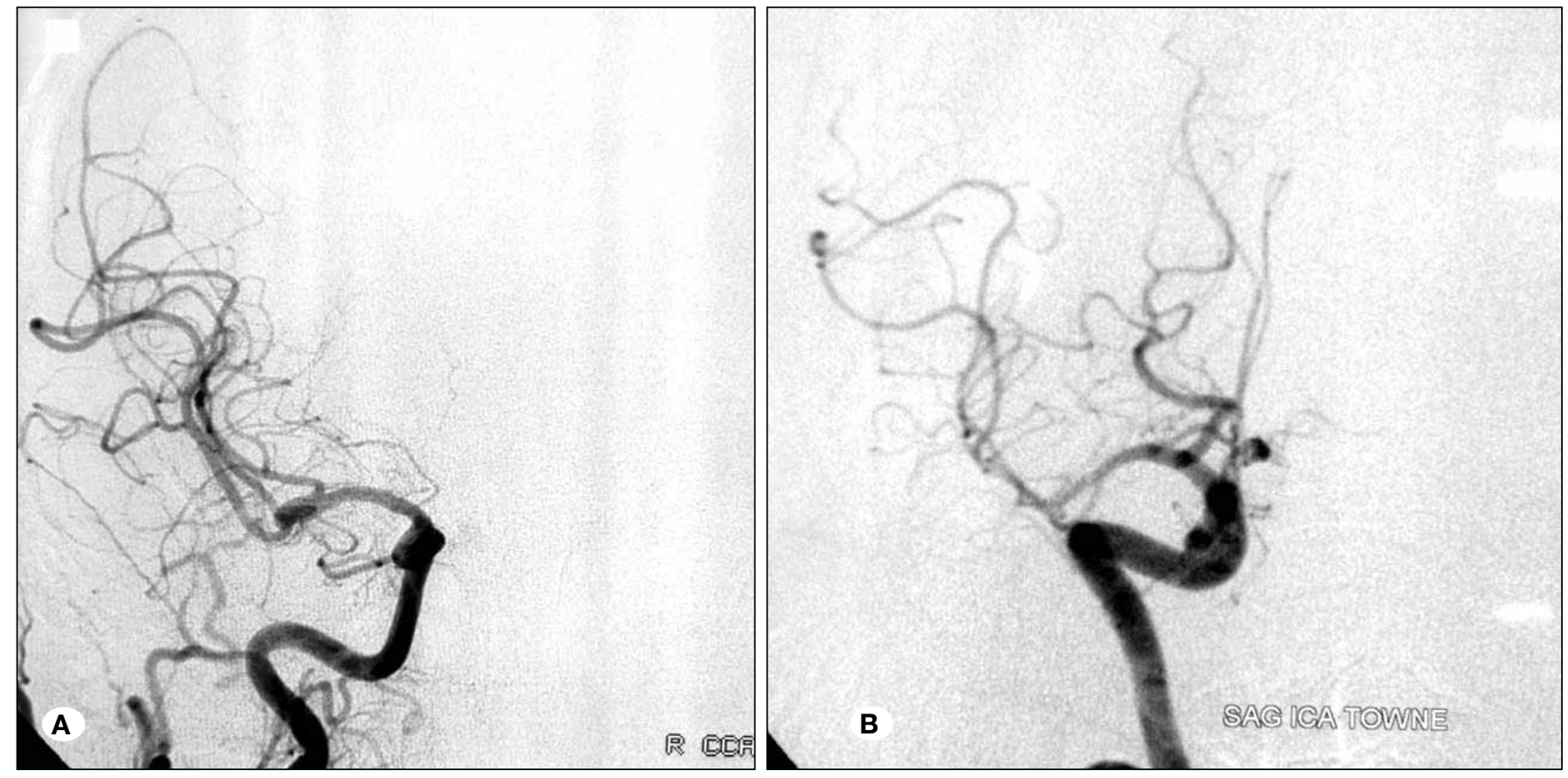

Figure 4: DSA examination showing examples of multiple variations. A) Right MCA trifurcation and A1 aplasia. B) Fetal circulation and A1 aplasia. 
MCS variation rate and aneurysm coexistence showed no statistically significant difference in any localization (Table IV).

\section{Multiple Variations}

The rates of single and multiple anomalies were $24 \%$ and $28 \%$, respectively. There were two anomalies in $20 \%$ of the cases and more than two anomalies in $8 \%$ of the cases. Multiple variation rates were significantly higher in PCS cases $(p=0.001 ; p<0.01)$ (Table V).

\section{Bleeding \& Non-bleeding Aneurysm, Number and Localization of Aneurysm}

The vascular variations were more common in bleeding aneurysms $(61.3 \%$ versus $40.9 \%)$. The rate of multiple variations was also higher in bleeding aneurysms $(18.9 \%$ versus $9.1 \%$ ). There was no significant difference, either in variable rates $(p=0.127 ; p>0.05)$ or in the number of variations $(p=0.716 ; p>0.05)$, between bleeding/non-bleeding cases.

According to the aneurysm number, variation rates $(p=0.291$; $p>0.05)$ and variation number rates $(p=0.364 ; p>0.05)$ were not statistically significantly related.

In single aneurysm cases, there was no statistically significant difference between cases related with the aneurysm diameter $(p=0.659 ; p>0.05)$.

There was no statistically significance between the aneurysm and number variation rates in any localization $(p>0.05)$. In single or multiple variation cases, there was no ICA aneurysm presence.

\section{DISCUSSION}

\section{Incidence}

In the present study, the overall rate of variations in the circle of Willis configuration with berry aneurysms was $57.8 \%$. The rate of variations in series with accompanying intracranial aneurysms was between $40.7 \%$ and $97 \%(2,12,20,27,32,33)$. In a recent cadaveric study conducted on the Turkish population, adult configuration of the polygon was detected in $87 \%$ (11). In cadaveric brains with unknown cause of death, Gunnal et al. (6) found gross morphological variations in $40 \%$ of the cases. Kapoor et al. (10) reported variations in $54.8 \%$ of 1000 medical autopsies. Qiu et al. (27) found the incidence of partial integrity and non-integrity as $70.17 \%$ and $17.59 \%$ respectively in 2,146 healthy subjects that were examined with magnetic resonance imaging (MRI) and magnetic resonance angiography (MRA).

\section{Variations}

We found that the most common anomaly was hypoplasia in the Willis polygon, similar to other series $(1,6,8,9,29)$. It was mostly seen in the A1 segment, followed by the P1 segment. Aplastic/hypoplastic $A 1$ was also the most common variation in some reports $(17,33)$. The incidence of hypoplastic and aplastic $A 1$ segment of the anterior cerebral artery was reported as $36 \%$ by Kryzewski et al. (16). In an MRI study investigating anterior cerebral artery variations, the A1 segment aplasia rate was only $5.6 \%$ (36). The fenestration of the $A 1$ and/or A2 segment was found to be $1.2 \%$. Kovac et al. (13) reported that the patients had hypoplastic or congenital absence of A1 segment at a rate of $17.6 \%$ and $0.4 \%$, respectively. Fetal origin of the posterior cerebral artery was found in $37 \%$ of the cases. In their series, lqbal et al. (8) stated a hypoplasia in PCoA rate of $24 \%$ that was followed by hypoplasia in the P1, A1 and ACoA segments. Similarly, Karatas et al. (11) found hypoplasia most commonly in the PCoA. The hypoplasia of A1 was frequently associated with $A C o A$ aneurysms and this is compatible with our results (26).

Although we detected only one fenestration in this study, Suziki et al. (34) reported $75 \%$ fenestration in 38 cases of ACA aneurysms in their surgical series. Two-dimensional images are thought to be unsuitable for detecting intracranial arterial fenestrations because of superimposition of vessels that may render their identification $(17,34)$. In a recent study, including patients with subarachnoid hemorrhage, van Rooij et al.(39) found $24 \%$ fenestration by 3D rotational angiography. In a study with CT angiography, the fenestrations of middle cerebral artery $\mathrm{M} 1$ segment $(0.2 \%)$, anterior communicating artery $(0.4 \%)$, and anterior cerebral artery $\mathrm{A} 1$ segment $(0.6 \%)$

Table V: ACS, PCS and MCS Variation Rates according to the Number of Aneurysms

\begin{tabular}{|c|c|c|c|c|}
\hline & & \multicolumn{2}{|c|}{ Number of variations } & \multirow{2}{*}{$\mathbf{p}$} \\
\hline & & n (\%) & n (\%) & \\
\hline \multirow{2}{*}{ ACS variation } & No & $21(77.8)$ & $6(22.2)$ & \multirow{2}{*}{${ }^{\mathrm{a}} 0.420$} \\
\hline & Yes & $31(66.0)$ & $16(34.0)$ & \\
\hline PCS variation & Yes & $14(45.2)$ & $17(54.8)$ & ${ }^{\mathrm{a}} 0.001^{*}$ \\
\hline \multirow{2}{*}{ MCS variation } & No & $44(72.1)$ & 17 (27.9) & \multirow{2}{*}{ '0.510 } \\
\hline & Yes & $8(61.5)$ & 5 (38.5) & \\
\hline
\end{tabular}

${ }^{a}$ Yates Continuity Correction, ${ }^{b}$ Fisher. 
were also noted (13). Fenestration may be seen even in the A2 segment of the anterior cerebral artery (4).

Krayenbuhl and Yaşargil (15) reported vertebral artery fenestration or anomalous termination. Gunnal et al. (7) found morphological variations in termination in $17.64 \%$ of the cases. The prevalence of fenestrations of the intracranial VB system was reported to be between $1.17 \%$ and $2.77 \%(7,13,37)$.

We detected P1 hypoplasia/aplasia in $28 \%$ of the cases in the presented study. Iqbal et al.(8) reported a $10 \%$ variation rate for fetal PCA. Gunnal et al.(6) found that the most common variation rate was in the $\mathrm{PCoA}$ with $50 \%$, followed by $\mathrm{ACoA}$ with $33.3 \%$. Malamateniou et al. (21) stated that the most common variation was PCoA aplasia $(30 \%)$ in the neonatal group. Saeki and Rhoton (30) reported that PCoA hypoplasia was unilateral in $26 \%$ of the cases and bilateral in $6 \%$ of the cases. The rate of a fetal configuration in which the PCA was arising predominantly from the carotid artery was $20 \%$ and $2 \%$ for unilaterally and bilaterally respectively. Yasargil (40) reported that the rate of the fetal type of circulation was $24.5 \%$ with much greater frequency on the right. Qiu et al. (27) demonstrated an incidence of $15.85 \%$ for P1 variation.

Gibo et al. (5) found that MCA anomalies are less common than the other anomalies consisting of duplicate or accessory MCA. They observed MCA trifurcation in $12 \%$ of the cases. This was similar to our study; MCA anomalies were the least common with $10.2 \%$ and, trifurcation was the most common variation with $7 \%$.

\section{Variation \& Number, Localization of Aneurysm}

Some specific aneurysms can be encountered together with some variations. Although ACA variations were seen commonly with $A C o A$ aneurysms $(p<0.01)$ in this study, there was no variation in 6 ICA aneurysm cases and this was statistically significant $(p<0.01)$. A1 segment variations have been reported more frequently in ACoA aneurysm cases than in the control group $(14,28)$. Suzuki et al. (34) reported $75 \%$ and Van Rooij et al. (39) reported $31 \%$ fenestration of ACoA that accompanied the aneurysm. In a study that investigated anatomic variations and recurrence rates of patients undergoing coil-embolization with aneurysms, A1 dominance on one side with ACoA aneurysms was found to be $73 \%$. A1 dominant flow was shown to act in aneurysm formation, growth and instability after coil embolization treatment (35). Kryzewski et al. (16) suggested that $A 1$ and $A 2$ segment anomalies of the anterior cerebral artery may potentially be associated with aneurysm formation. Although the clinical significance of ACA variations is usually minor, an associated aneurysm is found relatively frequently (36).

Songsaeng et al. (31) reported more frequent $A C o A, P C o A$ and BA aneurysm coincidence with $\mathrm{A} 1$ aplasia and fetal PCoA. Notably, asymmetrical $A 1$ segment and asymmetrical basilar apex presence were associated with recurrence following coil embolization.

There was an inverse relation for PCoA and MCA aneurysms. In ACS variations, PCoA and MCA aneurysm coexistence $(p<0.05)$ was significantly lower than in cases without ACS variation. There was no statistically significant difference between other aneurysm localizations and anterior system variation presence.

Macchi et al. (19) proposed that anatomic variation rates were higher in the left side, but we found a higher variation rate on the right side in the ACS group.

Stojanovic et al. (33) reported a Willis asymmetry prevalence of $64 \%$ in their series; in multiple aneurysms this rate increased to $75.7 \%$. It was found to be $61.1 \%$ and $48.5 \%$ for accompanying single and multiple aneurysms respectively in the present study but there was no statistical significance. Mazighi et al. (22) reported that vascular anomalies were associated with aneurysm development and bleeding. Vascular anomalies were found in $88 \%$ of the patients with multiple intracranial aneurysms. The most common anomaly was the asymmetric caudal basilar fusion (43.2\%) followed by variations of the anterior communicating artery (ACoA) complex (31.2\%). The aneurysm bled proportionally more frequently when associated with the related vascular anomaly (22). Nurminen et al. (24) found major anatomic variations affecting cerebral arteries in $2 \%$ of the patients with giant intracranial aneurysms.

Willis variations were encountered frequently, particularly in ACoA and PCoA aneurysms $(5,12,14,20)$. Asymmetrical $A 1$ and $A C O A$ aneurysms show this association, as well as asymmetrical PCoA and PCoA aneurysms. The association between variation and aneurysm localization supports the role of hemodynamic factors in the pathogenesis.

In several aneurysm cases, more than one variation can be observed (12). In our study, a single variation was observed in $40.6 \%$ of the cases; the rate was $17.2 \%$ for multiple variations. Multiple variations were 2 in number in 18 cases, and 3 in 4 cases.

\section{Bleeding \& Non-Bleeding Aneurysms}

High Willis asymmetry rates in bleeding aneurysms confirm the relationship between hemodynamic disturbance due to asymmetric configuration and aneurysm formation and rupture $(3,4,7,12,13,15,23,26,29,33)$. In bleeding ACoA aneurysms, Stojanovic et al. (33) reported that the asymmetry presence accounted for $72.7 \%$; morphological changes were present in the $A 1$ segment (44\%) and mainly on the right side (60\%).

Lazzaro et al. (18) found the Willis anomaly in $46.9 \%$ of bleeding aneurysms and $29.6 \%$ of non-bleeding (incidental) aneurysms, and proposed that aneurysm rupture rates were higher in the presence of a Willis anomaly. They stated that the Willis anomaly was more common in bleeding anterior and posterior communicating artery aneurysms than in non-bleeding aneurysms.

Van Rooij et al. (39) reported 31\% fenestration of ACoA where an accompanying aneurysm caused $\mathrm{SAH}$

In the present study, compatible with Lazzaro et al. (18), variation presence was more common in bleeding aneurysm cases than in non-bleeding aneurysm cases at $61.3 \%$ and $40.9 \%$ respectively. The multiple variation rate was higher in bleeding aneurysms at $18.9 \%$ versus $9.1 \%$. However, there 
was no significant difference between bleeding/non-bleeding cases on statistical analysis, either in the variable rates $(p=0.127 ; p>0.05)$ or in the number of variations $(p=0.716$; $\mathrm{p}>0.05$ )

\section{Gender Relationship}

Van Overbeeke et al. (38) reported no significant frequency difference regarding gender or right-left side in the adult or fetal configuration in fetal and infant brains. They noted that variations occur as developmental modifications more than genetic factors. Malamateniou et al. (21) found that complete Willis variation rates were higher in preterm girls, and ACoA and $\mathrm{P} 1$ segment aplasia-hypoplasia was two times higher in term-born girls, whereas PCoA and A1 segment aplasiahypoplasia were more frequent in preterm boys. In term-born infants, the fetal type of PCA is twice as frequent in the left side. In the present study, there was no difference in rates in the ACS and PCS groups considering the gender of cases, but MCA variation rates in males were significantly higher $(p=0.031 ; p<0.05)$. In contrast, Krzyżewski et al. (16) reported that males had significantly higher prevalence of the typical ACoA complex.

The limitations of this study are as follows:

- The detected vascular variations in this study were all in patients who were subject to subarachnoid hemorrhage and/or cerebral aneurysm. These variations give no information about normal/healthy cases. Cadaveric studies may provide more accurate knowledge about natural anatomy, but the aim of this paper was to show the arterial variations in patients with an intracranial vascular insult.

- All the images are 2-dimensional, and 2-dimensional images may not be suitable for detecting intracranial arterial fenestrations.

\section{- CONCLUSION}

There was an association between aneurysm localization and vascular variations. In the present study, rate of variations in the circle of Willis configuration in patients with berry aneurysms was $57.8 \%$. Arterial hypoplasia and aplasia were the most common vascular variations associated with intracranial aneurysms. ACS was the most common region that variations were located in; they were mostly detected on the right side. In the ACS variations group, coexistence of ACoA aneurysm was higher than with PCoA and MCA aneurysms. In the PCS variations group, $\mathrm{PCoA}$ aneurysms were the most common aneurysms that accompanied the variation. In the PCS variation group, multiple variations were more common than in the other two groups. The vascular variations in MCS were most common in males.

Knowledge/awareness of these variations would guide choosing and applying treatment modalities, and increase the success rate in managing the patients.

\section{- REFERENCES}

1. Alpers BJ, Berry RG, Paddison RM: Anatomical studies of the circle of Willis in normal brain. Arch Neurol Psychiatry 81: 409418, 1959

2. Aydin IH, Takci E, Kadioglu HH, Tuzun Y, Kayaoglu CR, Barlas $\mathrm{E}$ : Vascular variations associated with anterior communicating artery aneurysms-an intraoperative study. Minim Invasive Neurosurg 40(1):17-21, 1997

3. Biondi A: Intracranial aneurysms associated with other lesions, disorders or anatomic variations. Neuroimag Clin N Am 16:467-482, 2006

4. Dimmick SJ, Faulder KC: Fenestrated anterior cerebral artery with associated arterial anomalies. Case reports and literature review. Interv Neuroradiol 14: 441-445, 2008

5. Gibo H, Carver CC, Rhoton AL Jr, Lenkey C, Mitchell RJ: Microsurgical anatomy of the middle cerebral artery. J Neurosurg 54(2):151-169, 1981

6. Gunnal SA, Farooqui MS, Wabale RN: Anatomical variations of the Circulus Arteriosus in cadaveric human brains. Neurol Res Int 2014:687281, 2014

7. Gunnal S, Farooquı M, Wabale R: Anatomical variability in the termination of the basilar artery in the human cadaveric brain. Turk Neurosurg 25(4):586-594, 2015

8. Iqbal S: A comprehensive study of the anatomical variations of the Circle of Willis in adult human brains. J Clin Diagn Res 7(11):2423-2427, 2013

9. Kamath S: Observations on the length and diameter of the vessels forming the circle of Willis. J Anat 133: 419-423, 1981

10. Kapoor K, Singh B, Dewan LI: Variations in the configuration of the circle of Willis. Anat Sci Int 83:96-106, 2008

11. Karatas A, Yilmaz $H$, Coban G, Koker M, Uz A: The Anatomy of Circulus Arteriosus Cerebri (Circle of Willis): A study in Turkish population. Turk Neurosurg 26(1):54-61, 2016

12. Kayembe KN, Sasahara M, Hazama F: Cerebral aneurysms and variations in the circle of Willis. Stroke 15:846-850, 1984

13. Kovač JD, Stanković A, Stanković D, Kovač B, Šaranović D: Intracranial arterial variations: A comprehensive evaluation using CT angiography. Med Sci Monit 20: 420-427, 2014

14. Krasny A, Nensa F, Sandalcioglu IE, Göricke SL, Wanke I, Gramsch C, Sirin S, Oezkan N, Sure U, Schlamann M: Association of aneurysms and variation of the A1 segment. J Neurointerv Surg 6 (3):178-183, 2014

15. Krayenbuhl $H$, Yasargil $M$ : Cerebral angiography. London: Butterworths, 1968: 72

16. Krzyżewski RM, Tomaszewska IM, Lorenc N, Kochana M, Goncerz G, Piotrowska WK, Walocha K, Urbanik A: Variations of the anterior communicating artery complex and occurence of anterior communicating artery aneurysm: A2 segment. Consideration Folia Medica Cracoviensia 54:13-20, 2014

17. Krzyżewski RM, Tomaszewski KA, Kochana M, Kopeć M, Klimek-Piotrowska W, Walocha JA: A rare anatomical variant: Median anterior cerebral artery fenestration associated with an azygous infra-optic anterior cerebral artery. Surg Radiol Anat 37(1):81-86, 2015 
18. Lazzaro MA, Ouyang B, Chen M: The role of circle of Willis anomalies in cerebral aneurysm rupture. J Neurointerv Surg 4(1): 22-26, 2012

19. Macchi C, Lova RM, Miniati B, Gulisano M, Pratesi C, Conti AA, Gensini GF: The circle of Willis in healthy older persons. J Cardiovasc Surg (Torino) 43: 887-890, 2002

20. Mackenzie JM: The anatomy of aneurysm-bearing circles of Willis. Clin Neuropathol 10(4):187-189, 1991

21. Malamateniou C, Adams ME, Srinivasan L, Allsop JM, Counsell SJ, Cowan FM, Hajnal JV, Rutherford MA: The anatomic variations of the Circle of Willis in preterm-at-term and term-born infants: An MR angiography study at 3T. Am J Neuroradiol 30:1955-1962, 2009

22. Mazighi M, Porter PJ, Rodesch G, Alvarez H, Aghakhani N, Lasjaunias P: Vascular anomalies and the risk of multiple aneurysms development and bleeding. Interv Neuroradiol 8: 15-20, 2002

23. Nixon AM, Gunel M, Sumpio BE: The critical role of hemodynamics in the development of cerebral vascular disease. J Neurosurg 112:1240-1253, 2010

24. Nurminen V, Lehecka M, Chakrabarty A, Kivisaari R, Lehto $H$, Niemelä M, Hernesniemi J: Anatomy and morphology of giant aneurysms-angiographic study of 125 consecutive cases. Acta Neurochir 156:1-10, 2014

25. O'Connor JP: Thomas Willis and the background to Cerebri Anatome. J R Soc Med 96(3): 139-143, 2003

26. Perlmutter D, Rhoton AL: Microsurgical anatomy of the anterior cerebral - anterior communicating - recurrent artery complex. J Neurosurg 45:259-472, 1976

27. Qiu C, Zhang Y, Xue C, Jiang S, Zhang W: MRA Study on variation of the Circle of Willis in healthy Chinese male adults. Biomed Res Int 2015:976340, 2015

28. Rhoton AL Jr: The supratentorial arteries. Neurosurgery 51 (4 Suppl): S53-120, 2002

29. Riggs HE, Rupp C: Variation in form of circle of Willis. The relation of the variations to collateral circulation: Anatomic analysis. Arch Neurol 8:8-14, 1963
30. Saeki N, Rhoton AL Jr: Microsurgical anatomy of the upper basilar artery and the posterior circle of Willis. J Neurosurg 46: 563-578, 1977

31. Songsaeng $D$, Geibprasert $S$, Willinsky $R$, Tymianski $M$, TerBrugge KG, Krings T: Impact of anatomical variations of the Circle of Willis on the incidence of aneurysms and their recurrence rate following endovascular treatment. Clin Radiol 65(11): 895-901, 2010

32. Stehbens WE: Etiology of intracranial berry aneurysms. J Neurosurg 70(6):823-831, 1989

33. Stojanović N, Stefanović I, Randjelović S, Mitić R, Bosnjaković $\mathrm{P}$, Stojanov D: Presence of anatomical variations of the Circle of Willis in patients undergoing surgical treatment for ruptured intracranial aneurysms. Vojnosanit Pregl 66 (9):711-717, 2009

34. Suzuki M, Onuma T, Sakurai Y, Mizoi K, Ogawa A, Yoshimoto $\mathrm{T}$ : Aneurysms arising from the proximal (A1) segment of the anterior cerebral artery. A study of 38 cases. J Neurosurg 76(3):455-458, 1992

35. Tarulli E, Sneade M, Clarke A, Molyneux AJ, Fox AJ: Effects of circle of Willis anatomic variations on angiographic and clinical outcomes of coiled anterior communicating artery aneurysms. Am J Neuroradiol 35(8):1551-1555, 2014

36. Uchino A, Nomiyama K, Takase Y, Kudo S: Anterior cerebral artery variations detected by MR angiography. Neuroradiology 48: 647-652, 2006

37. Uchino A, Saito N, Okada Y, Kozawa E, Nishi N, Mizukoshi W, Inoue K, Nakajima R, Takahashi M: Fenestrations of the intracranial vertebrobasilar system diagnosed by MR angiography. Neuroradiology 54:445-450, 2012

38. van Overbeeke JJ, Hillen B, Tulleken CAF: A comparative study of the circle of Willis in fetal and adult life. The configuration of the posterior bifurcation of the posterior communicating artery. J Anat 176: 45-54, 1991

39. van Rooij SB, Bechan RS, Peluso JP, Sluzewski M, van Rooij WJ: Fenestrations of intracranial arteries. AJNR Am J Neuroradiol 36 (6):1167-1170, 2015

40. Yasargil MG: Microsurgical Anatomy of the Basal Cisterns and Vessels of the Brain, Diagnostic Studies, General Operative Techniques and Pathological Considerations of the Intracranial Aneurysms. Microneurosurgery Vol: 1, Stuttgart, New York:Thieme, 1984 